\title{
Zika virus and microcephaly
}

\author{
Michelle A. Barton MBBS MSc, Marina I. Salvadori MD
}

Competing interests: None declared.

This article has been peer reviewed.

Correspondence to:

Michelle Barton,

mbartonf@uwo.ca

CMAJ 2016. DOI:10.1503

/cmaj.160179
$\mathrm{B}$ efore 2015, Zika virus, a mosquitotransmitted flavivirus endemic to Africa and Southeast Asia, was thought to cause only a mild, self-limiting dengue-like illness. First discovered in 1947 in Uganda, the virus became epidemic in the Pacific islands 10 years ago. Several countries throughout South and Central America and the Caribbean are now affected. Recent reports of a surge in cases of microcephaly coincident with Zika virus activity in Brazil have raised concerns about the harms to the fetuses of infected pregnant women. ${ }^{1}$

Detection of Zika virus RNA in placenta, amniotic fluid and fetal losses, as well as in the brains of deceased infants with microcephaly, ${ }^{2}$ has confirmed that vertical transmission occurs. However, there is insufficient evidence to determine causality. Data supporting the hypothesis that Zika virus causes microcephaly include experimental data in infant mice showing the virus to be neurotropic; ${ }^{3}$ a subsequent report of a similar surge in central nervous system malformations in French Polynesia related to the outbreak there, with an estimated risk of $1 \%$ in first-trimester infections, ${ }^{2,4}$ fetal ultrasonographic abnormalities in $29 \%$ of pregnant women $(n=12 / 42)$ with rash who were positive for the virus and in none of the pregnant women with rash $(n=16)$ who were negative for the virus in a cohort study in Brazil $; 5$ and the presence of intracranial calcifications similar to that seen in congenital infections. ${ }^{2}$ Working against the hypothesis are observations of brainstem abnormalities atypical for infection ${ }^{6}$ and a preliminary report of low prevalence $(8.9 \%)$ of Zika virus infection among 462 infants in Brazil with microcephaly or anomalies in the central nervous system. ${ }^{1}$ Alternate hypotheses,

including larvicide exposure, were refuted in a recent report by the World Health Organization.?

A recent study in Brazil involving a cohort of 35 infants with microcephaly and who tested negative for other congenital infections showed that $74 \%$ had severe microcephaly, $31 \%$ had rugose scalp and $11 \%$ had arthrogryposis. Findings on neuroimaging resembled those in congenital cytomegalovirus infection. Three-quarters of their mothers had a history of rash in the first or second trimester. ${ }^{8}$ At the time of writing, results of testing for Zika virus are pending for this cohort. Maternal symptoms of illness were reported before or at 20 weeks gestation ${ }^{1,3,8}$ - the period during which cell proliferation (weeks 5-20) and cell migration (weeks 6-24) occur - which is consistent with the pattern of abnormalities observed, given known timelines for brain development. Abnormalities of the infant central nervous system have been reported in maternal infections as late as 27 weeks' gestation. ${ }^{5}$

Infections occurring during the first trimester have the most profound impact on the developing fetus and often threaten viability. They may affect cellular proliferation and differentiation, which leads to organ malformations and growth limitation. Neurotropic viruses (e.g., cytomegalovirus) target specific brain cells, where they replicate and cause focal necrosis either directly or indirectly via proinflammatory pathways and subsequently result in severe microcephaly. ${ }^{9}$ Neurotropic flaviviruses (e.g., West Nile virus and Japanese encephalitis virus) can also be transmitted to the fetus, but the clinical spectrum is different, with only sporadic cases of microcephaly reported for West Nile virus infection. ${ }^{10}$ Microcephaly may occur beyond the first trimester when infectious, toxic or vascular insults arrest normal brain development (i.e., fetal brain disruption sequence) ${ }^{11}$ and result in overlapping sutures and wrinkling of the redundant scalp, similar to the rugose scalp appearance reported in $31 \%$ of the cohort in Brazil. ${ }^{8}$ Some of the noted atypical brainstem abnormalities may be consistent with this pathologic process.

In a cohort study of 26 children with congenital cytomegalovirus infection, microcephaly (determined using head circumference adjusted for weight) showed high specificity for predicting cognitive and motor deficits, whereas neuroimaging 
was sensitive for these outcomes. ${ }^{12}$ In addition, epilepsy was associated with microcephaly, and visual and hearing loss was associated with neuroimaging abnormalities in this cohort. ${ }^{12}$ Most infants $(60 \%-$ $90 \%$ ) with congenital cytomegalovirus infection who are symptomatic at birth develop one or more long-term neurologic sequelae, compared with $15 \%$ of infants who are asymptomatic at birth. ${ }^{9}$ Extrapolating from the experience with congenital cytomegalovirus infection, severe neurodevelopmental morbidity, including visual and hearing loss and even epilepsy, could be expected among offspring born with microcephaly to mothers prenatally infected with Zika virus. However, infants with microcephaly may represent the tip of the iceberg; it would be prudent to systematically evaluate the vision, hearing and development of all infants with congenital Zika virus infection.

Preventing maternal infection is the only way to prevent vertical transmission of Zika virus, because antiviral treatment and vaccines are not available at present. The US Centers for Disease Control and Prevention recommends that pregnant women who do not reside in areas with Zika virus should avoid travel to affected countries. ${ }^{13}$ Until the role of sexual transmission is fully elucidated, pregnant women should abstain from or have protected sexual intercourse with partners who have recently travelled to countries with Zika virus. Travellers to and residents of affected countries should use universally recommended barriers to mosquito biting (e.g., mosquito repellant, long-sleeved shirts and long pants, bed nets and staying indoors in air-conditioned and/or screened-in rooms). ${ }^{13}$ Women of child-bearing age who are not pregnant should use contraceptive methods to delay pregnancy until the outbreak ends or until they are immune.

For pregnant women who acquire a rash or fever associated with possible exposure to Zika virus, only supportive treatment is available. Although there is no specific treatment, affected women should undergo testing to facilitate careful obstetric care and counselling where appropriate. Serologic assays are useful for diagnosing convalescent infections but pose challenges with interpretation because of the cross reactivity that occurs with other flaviviruses. Zika virus reverse transcription-polymerase chain reaction is an excellent diagnostic test in acute illness but is limited by a short window of detection. ${ }^{13}$ The turnaround time for national testing ( $14 \mathrm{~d}$ ) may be delayed if exposure to other flaviviruses has occurred. Asymptomatic pregnant women with potential exposure to the virus should also be tested. All pregnant women exposed to Zika virus should have serial fetal ultrasonography. If abnormalities are detected, amniocentesis may be offered beyond 15 weeks gestation to aid diagnosis. ${ }^{13}$
If ongoing studies confirm a causal association between congenital Zika virus infection and irregularities in fetal development, the virus' potential for devastating impact on fetal survival and infant neurodevelopmental health will become clearer. Development of a Zika virus vaccine is currently a high priority. However, intensifying public health measures to prevent infection will be equally important. Future research should be directed at understanding the factors that promote vertical transmission and at identifying potential therapeutic strategies for reducing vertical transmission, in particular, antiviral agents with specific activity against Zika virus, and exploring the role of adjunctive interventions (e.g., intravenous immunoglobulins or pooled Zika virus-specific immunoglobulins).

\section{References}

1. Rapid risk assessment. Zika virus disease epidemic: potential association with microcephaly and Guillain-Barré syndrome. Third update, 23 February 2016. Stockholm: European Centre for Disease Prevention and Control; 2016. Available: ecdc. europa.eu/en/publications/Publications/zika-virus-rapid-risk -assessment-23-february-2016.pdf (accessed 2016 Mar. 1).

2. Rapid risk assessment. Zika virus epidemic in the Americas: potential association with microcephaly and Guillain-Barré syndrome. First update, 21 January 2016. Stockholm: European Centre for Disease Prevention and Control; 2016. Available: ecdc.europa.eu/ en/publications/Publications/zika-virus-americas-association-with -microcephaly-rapid-risk-assessment.pdf (accessed 2016 Mar. 1).

3. Bell TM, Field EJ, Narang HK. Zika virus infection of the central nervous system of mice. Arch Gesamte Virusforsch 1971;35:183-93.

4. Cauchemez S, Besnard M, Bompard P, et al. Association between Zika virus and microcephaly in French Polynesia, 2012-15: a retrospective study. Lancet 2016 Mar. 15 [Epub ahead of print]

5. Brasil P, Pereira JP Jr, Raja Gabaglia C, et al. Zika virus infection in pregnant women in Rio de Janeiro - preliminary report. N Engl J Med 2016 [Epub ahead of print].

6. Oliveira Melo AS, Malinger G, Ximenes R, et al. Zika virus intrauterine infection causes fetal brain abnormality and microcephaly: Tip of the iceberg? Ultrasound Obstet Gynecol 2016;47:6-7.

7. Dispelling rumours around Zika and microcephaly (updated 2016 Mar. 11). Geneva: World Health Organization. Available: www. who.int/emergencies/zika-virus/articles/rumours/en/ (accessed 2016 Mar. 14).

8. Schuler-Faccini L, Ribeiro EM, Feitosa IM, et al. Possible association between Zika virus infection and microcephaly Brazil, 2015. MMWR Morb Mortal Wkly Rep 2016;65:59-62.

9. Cheeran MCJ, Lokensgard JR, Schleiss MR. Neuropathogenesis of congenital cytomegalovirus infection: disease mechanisms and prospects for intervention. Clin Microbiol Rev 2009;22:99-126.

10. O'Leary DR, Kuhn S, Kniss KL, et al. Birth outcomes following West Nile virus infection of pregnant women in the United States: 2003-2004. Pediatrics 2006;117:e537-45.

11. Russell LJ, Weaver DD, Bull MJ, et al. In utero brain destruction resulting in collapse of the fetal skull, microcephaly, scalp rugae, and neurologic impairment: the fetal brain disruption sequence. Am J Med Genet 1984;17:509-21.

12. Alarcon A, Martinez-Biarge M, Cabañas F, et al. Clinical, biochemical, and neuroimaging findings predict long-term neurodevelopmental outcome in symptomatic congenital cytomegalovirus infection. J Pediatr 2013;163:828-34.e1.

13. Oduyebo T, Petersen EE, Rasmussen SA, et al. Update: interim guidelines for health care providers caring for pregnant women and women of reproductive age with possible Zika virus exposure United States, 2016. MMWR Morb Mortal Wkly Rep 2016;65:122-7.

Affiliation: Division of Paediatric Infectious Diseases, Department of Paediatrics, University of Western Ontario, London, Ont.

Contributors: Both authors wrote the manuscript and revised it critically for intellectual content, gave final approval for the version to be published and agreed to act as guarantors of the work. 